University of Nebraska - Lincoln

DigitalCommons@University of Nebraska - Lincoln

Faculty Publications: Department of Entomology

Entomology, Department of

March 2007

\title{
Candidate sex pheromones of the New World screwworm Cochliomyia hominivorax
}

\author{
D.A. Carlson \\ USDA-ARS \\ Dennis Berkebile \\ USDA-ARS, DENNIS.BERKEBILE@ars.usda.gov \\ S.R. Skoda \\ USDA-ARS \\ K. Mori \\ Fuji Flavor Co. Ltd., Tokyo, Japan \\ S. Mihok \\ Russell, Ontario, Canada
}

Follow this and additional works at: https://digitalcommons.unl.edu/entomologyfacpub

Part of the Entomology Commons

Carlson, D.A.; Berkebile, Dennis; Skoda, S.R.; Mori, K.; and Mihok, S., "Candidate sex pheromones of the New World screwworm Cochliomyia hominivorax" (2007). Faculty Publications: Department of Entomology. 30.

https://digitalcommons.unl.edu/entomologyfacpub/30

This Article is brought to you for free and open access by the Entomology, Department of at DigitalCommons@University of Nebraska - Lincoln. It has been accepted for inclusion in Faculty Publications: Department of Entomology by an authorized administrator of DigitalCommons@University of Nebraska - Lincoln. 


\title{
Candidate sex pheromones of the New World screwworm Cochliomyia hominivorax
}

\author{
D. A. CARLSON ${ }^{1}, D \cdot R \cdot B E R K E B I L E{ }^{2}, S \cdot R \cdot S_{K O D A}^{2}, K \cdot M_{O R I}^{3}$ \\ and S. MIHOK ${ }^{4}$ \\ ${ }^{1}$ U.S. Department of Agriculture (USDA), Agricultural Research Service (ARS), Center for Agricultural, Medical and Veterinary \\ Entomology, Gainesville, Florida, U.S.A., ${ }^{2}$ USDA, Midwest Livestock Insects Research Unit, Lincoln, Nebraska, U.S.A., ${ }^{3}$ Insect \\ Pheromone and Traps Division, Fuji Flavor Co. Ltd., Tokyo, Japan and ${ }^{4}$ Russell, Ontario, Canada
}

\begin{abstract}
Five novel homologous acetate derivatives of long-chain secondary alcohols and a related ketone were tested for their efficacy as contact mating stimulants for Cochliomyia hominivorax Coquerel (Diptera: Calliphoridae). Full copulatory behaviour at a high percentage was found in tests with racemic 6-acetoxy-19-methylnonacosane at 2.5-20 $\mu \mathrm{g}$ using fertile males from three strains. Males of two strains responded nearly as well to 7-acetoxy-15-methylnonacosane, but an older strain first colonized in 1992 did not respond to this compound. Few or no copulatory responses were obtained to the other secondary alcohol acetates and a related ketone. These two acetate derivatives are the first sex pheromones identified in a calliphorid fly. The threshold of response was also tested, but could not be pinpointed.
\end{abstract}

Key words. mate recognition, screwworm fly, sex pheromone, sterile insect technique.

\section{Introduction}

Large-scale programmes to eradicate the New World screwworm Cochliomyia hominivorax Coquerel using the sterile insect technique (SIT) have been successful in Libya (Lindquist et al., 1992), and in North and Central America (Galvin \& Wyss, 1996). A similar outcome has been elusive in Jamaica, despite a large effort that began in 1999. The reasons for slow progress are unclear, but one potential contributing factor may be a diminished tendency for certain strains of colony males to mate with wild females from Jamaica. A change in male response during colonization to the female mating stimulant pheromone may be involved. Factory males sometimes mate less readily with non-siblings after prolonged colonization (Mangan, 1988), although they maintain normal responses to siblings (Hammack, 1987).

A mating pheromone that can be removed with a lipid solvent is present in the cuticle of $C$. hominivorax females (Mackley \& Broce, 1981). The production and reception of this pheromone has been studied (Hammack, 1986). From mating studies using crude extracts and unseparated flies, strain variation and assortive mating occurred during prolonged colonization
(Hammack, 1987, 1991). In a first attempt to identify the compounds responsible, long-chain cuticular hydrocarbons were isolated (Pomonis \& Mackley, 1985). However, these extracts did not stimulate mating behaviour. With further purification, stimulatory material was obtained from a polar fraction separated by silica gel liquid chromatography and isocratic highperformance liquid chromatography. This fraction was further analysed by gas chromatography-mass spectrometry and was shown to contain 13 acetoxy homologues and a larger ketone, at $0.8 \mu \mathrm{g}$ total per female (Pomonis et al., 1993). The compounds represent six unbranched and seven branched acetates consisting of 29-carbon backbone secondary alcohols.

Pomonis et al. (1993) did not attempt to characterize the chiral character of the unseparated methyl-branched isomers. Subsequent thin-layer chromatography and preparative capillary gas chromatography (GC) failed to produce bioactive isolates. No natural compounds were ever separated into individual components despite repeated efforts, perhaps because they became lost or diluted during preparation. However, a decline in the quantity of the 29-carbon acetoxy components in this polar fraction was found in females that had been colonized for many years. From mass spectra of prevalent isomers, the total amount 
of material in wild females was about $100-125 \mu \mathrm{g}$ vs. 1-2 $\mu \mathrm{g}$ in females colonized for 10 years (J. G. Pomonis, personal communication). As no racemic compounds were prepared, and no other synthetic or natural compounds have ever stimulated mating in bioassays, we attempted to clarify the status of the sex pheromone in this insect by trials of newly synthesized materials. We tested the five most prevalent acetates of branched secondary alcohols and a related ketone as identified by Pomonis et al. (1993). The compounds were synthesized for the present trials (Furukawa et al., 2002). Here we report the biological activity of these sex pheromones.

\section{Materials and methods}

Non-irradiated males of three strains of $C$. hominivorax were used: Mexico 1984 (PA34), Panama 1995 (P95) and Jamaica 1998 (J2). Upon emergence, males were separated and maintained in the dark with carbohydrate and water at $23{ }^{\circ} \mathrm{C}$ for $5-7$ days (Hammack, 1987). Flies were transferred without anaesthesia to clear polystyrene chambers $(5 \times 5 \times 2 \mathrm{~cm})$ for each bioassay. Females were frozen, then pinned to use as positive controls. Pinned, frozen females after solvent washing with GCgrade n-hexane (Baxter/Burdick \& Jackson, Muskegon, MI, U.S.A.) or unwashed males were used as negative controls. Males were encouraged to make contact with the decoy three times by tapping the vial lightly. The highest response in a four-step progressive scale was recorded during each test, as in Carlson et al. (2005): (i) brief orientation to the decoy following contact; (ii) mounting; (iii) orientation to the copulatory position with the abdomen curving, and (iv) full copulatory response with repeated mating attempts including hypopygium extension. As few intermediate scores (i-iii) were recorded in relevant tests, results are presented as simple binary response in terms of the percentage of full copulatory responses (category iv only) with associated 95\% confidence intervals (normal approximation to the binomial distribution).

The following racemic compounds were tested: 6-acetoxy-19-methylnonacosane (1); 7-acetoxy-19-methylnonacosane (2); 8-acetoxy-19-methylnonacosane (3); 7-acetoxy15-methylnonacosane (4); 21-methylhentriacontan-7-one (5), and 5-acetoxy-19-methylnonacosane (6). The racemic compounds were approximately $89-98 \%$ pure as shown by capillary GC analysis (Furukawa et al., 2002) and confirmed by GC analyses conducted at our facility (data not shown). Initial bioassay doses were based on the approximate amount of biologically active material present in wild flies (100-125 $\mu \mathrm{g}$ total per female). Each compound was first tested at 2.5, 5, 10 and $20 \mu \mathrm{g}$ by dissolving a weighed amount of candidate compound (1.0 $\mathrm{mg}$ ) in hexane $(1 \mathrm{~mL})$. To prepare chemically treated decoys, a hexane-washed male was pinned and its wings were removed. The decoy was then treated with a microsyringe on the dorsum of the abdomen with $1 \mu \mathrm{L}$ n-hexane or the appropriate amount of test compound dissolved in hexane at $1 \mu \mathrm{g} / \mu \mathrm{L}$ or $0.1 \mu \mathrm{g} / \mu \mathrm{L}$. At least 1 min elapsed before introduction of each decoy into the chamber for trials against individual males from each colony strain. Fifteen replicates per combination were completed, with a similar number of positive controls by compound (pinned, frozen females). A second experiment was then conducted with strain P95 using two of the most stimulatory compounds $(1,4)$ at lower doses $(0.625,1.25,2.5$ and $5 \mu \mathrm{g})$.

\section{Results}

Males never showed any mating responses to negative controls. In the first experiment, no full copulatory responses were obtained to compounds 5 and 6 . Responses to positive controls approached $100 \%(93 \pm 6 \%, n=60)$, with no variation among strains $\left(\chi^{2}=1.6\right.$, d.f. $\left.=2, P=0.45\right)$. For compounds $1-4$, there were large differences in response among strains and compounds, but little variation with dose ( 8 of 9 possible $\chi^{2}$ tests with $P>0.05)$. Results were therefore pooled by strain/compound, and are shown in Fig. 1 ( $n=60$ for each combination). Differences within strains among the four compounds were highly significant (all $P<0.001$ ). Responses of about 40-60\% with $95 \%$ confidence intervals approaching controls were obtained for strains P95 and J2 with compounds 1 and 4. Much lower numbers of copulatory responses were obtained for compounds 2 and 3 (Fig. 1). Males of the strain with the longest period of colonization (PA34) responded to compound 1, as did P95 and J2 males, but PA34 males did not respond at all to any of the other compounds ( $0 \%$ response throughout).

In the second experiment with strain P95 only, there was no obvious dose-response relationship over a lower range of doses for compounds 1 and 4 (Fig. 2). Given the small sample sizes for each compound/dose $(n=15)$, differences in response among dose levels were not significant $\left(1: \chi^{2}=5.5\right.$, d.f. $=3, P=0.14$; 4: $\chi^{2}=1.6$, d.f. $\left.=3, P=0.66\right)$. The pooled responses to compound $1(63 \pm 12 \%)$, compound $4(70 \pm 12 \%)$ and the controls $(87 \pm 19 \%)$ did not differ significantly $\left(\chi^{2}=3.1\right.$, d.f. $=2, P=$ $0.21)$. Repeatability of the test in the two experiments for strain P95 was good (compound 1, $55 \pm 13 \%, 63 \pm 12 \%$; compound 4, $48 \pm 13 \%, 70 \pm 12 \%$ ), but the statistical power was insufficient to pinpoint the lower threshold of response. We also conducted

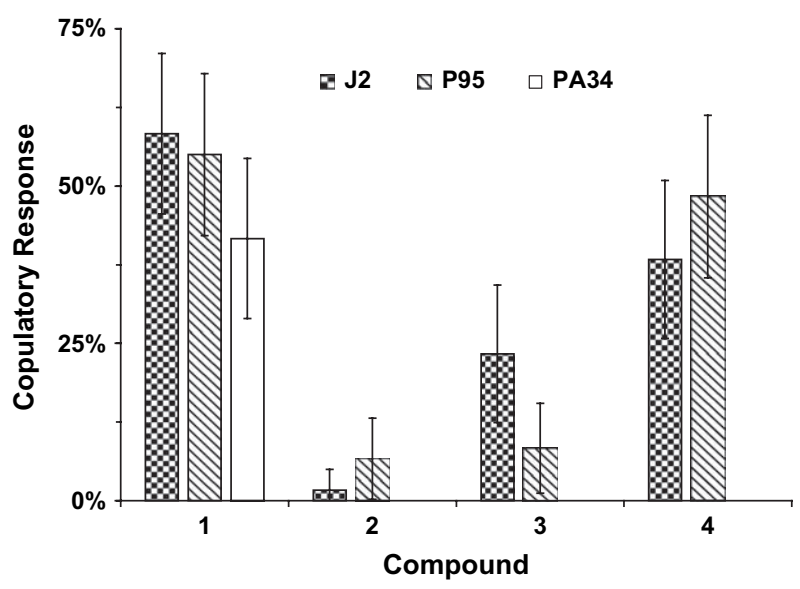

Fig. 1. Percentage of full copulatory responses in bioassays of three strains of New World screwworm colony males to hexane-washed decoy males treated with four compounds (mean $\pm 95 \%$ confidence interval, $n=60$ per bar pooled over $2.5-20 \mu \mathrm{g}$ ). 


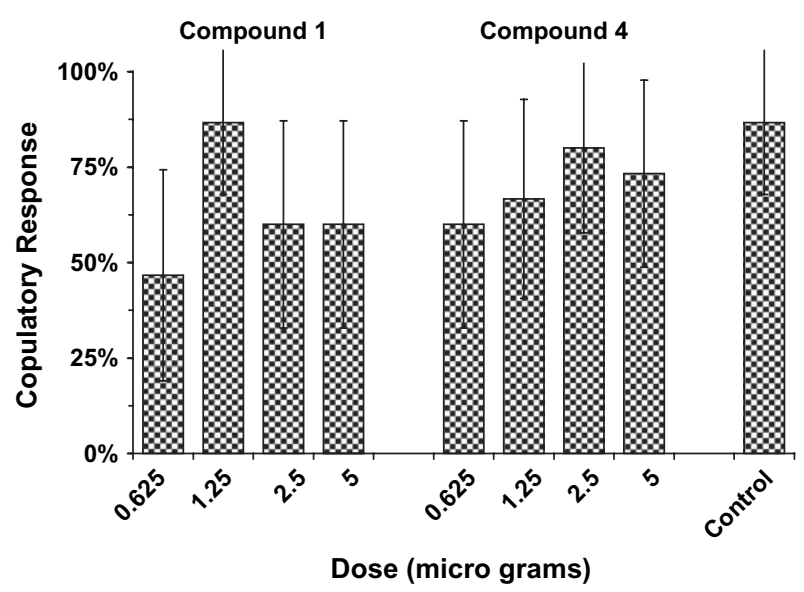

Fig. 2. Percentage of full copulatory responses of strain P95 to hexanewashed decoy males treated with compounds 1 or 4 (mean $\pm 95 \%$ confidence interval, $n=15$ per bar), at doses between $0.625 \mu \mathrm{g}$ and $5 \mu \mathrm{g}$.

preliminary trials of mixtures of compounds 1 and 4 to investigate possible synergism of stimulation at low, threshold dosages, but the results appeared rather similar to the results for the individual components. Unfortunately, pursuit of this interesting element was beyond the scope of our time-limited tests, as the fly colonies were scheduled to be destroyed.

\section{Discussion}

Of the six compounds tested, racemic 6-acetoxy-19-methylnonacosane (1) consistently stimulated full copulatory responses at requencies approaching those of positive controls in bioassays conducted with three strains of male screwworms at doses $\geq 2.5 \mu \mathrm{g}$. Full responses at high frequency were also obtained with 7-acetoxy15-methylnonacosane (4) for strains P95 and J2, but not for strain PA34. The threshold of response to compounds 1 and 4 could not be determined exactly in these tests, but appeared to be low (e.g. near $1 \mu \mathrm{g}$ ). Altogether, the present results are consistent with the hypothesis that these two acetoxy compounds from the female cuticle are the major components of the contact mating sex pheromone of $C$. hominivorax. This is the first time sex stimulant pheromones have been identified unequivocally in a calliphorid fly. Other bioactive compounds may also be present in the cuticular fraction, given the difficulty in achieving exactly the same high level of response as controls. Further studies are ongoing to test whether a $100 \%$ response can be achieved with chiral isomers of these two compounds.

Pomonis et al. (1993) found that extracts of females from longcolonized strains contained extremely low quantities of the presumed sex pheromone, particularly when compared with what is found in colonized houseflies. By contrast, laboratory female houseflies produce large amounts of (Z)-9-tricosene (Montooth \& Gibbs, 2003), an analogous sex pheromone (Carlson et al., 1971). Sex pheromone production in wild houseflies is usually much lower, rather than higher (Adler et al., 1984). If the finding of Pomonis et al. (1993) is typical for all long-colonized strains of screwworms (e.g. PA34), then colony males may be adapted to mating with females with low pheromone levels. Such males, when mass-reared and sterilized for release in a SIT campaign, may not react appropriately to wild females with substantially higher pheromone levels. Although this phenomenon has yet to be proven in the wild, it may be a contributing factor to unexpected results, as in the recent SIT campaign against this species in Jamaica. Altogether, cryptic, longterm changes in sex pheromone levels in screwworm colonies may have serious consequences for the successful mating of released sterile males. There may also be similar concerns for natural mating among siblings in captivity in large-scale rearing programmes. It may also be possible to use these compounds as indicators of quality assurance in large-scale rearing programmes.

\section{Acknowledgements}

The authors thank C. Geden, J. Schmidt, L. Hammack (U.S. Department of Agriculture, ARS), J. G. Pomonis (U.S. Department of Agriculture, retired), and B. Sutton (State of Florida, Department of Plant Industry, Gainesville) for helpful comments on the manuscript. It would be fitting to dedicate this article to Kenji Mori as it represents his last and prolonged effort before his recent retirement. We thank A. S. Robinson and J. Hendrichs, International Atomic Energy Agency, Vienna for partial support of this work.

\section{References}

Adler, V.E., Uebel, E.C. \& Schwarz, M. (1984) Production of (Z)-9tricosene by colonized and feral female houseflies. Southwestern Entomologist, 9, 223.

Carlson, D.A., Mayer, M.S., Silhacek, D.L., James, J.D., Beroza, M. \& Bierl, B.A. (1971) Sex attractant pheromone of the housefly: isolation, identification and synthesis. Science, 174, 76-78.

Carlson, D.A., Mramba, F., Sutton, B.D., Bernier, U.R., Geden, C.J. \& Mori, K. (2005) Sex pheromone of the tsetse species, Glossina austeni: isolation and identification of natural hydrocarbons, and bioassay of synthesized compounds. Medical and Veterinary Entomology, 19, 470-479.

Furukawa, A., Shibata, C. \& Mori, K. (2002) Synthesis of four methylbranched secondary acetates and a methyl-branched ketone as possible candidates for the female pheromone of the screwworm fly, Cochliomyia hominivorax. Bioscience Biotechnology and Biochemistry, 66, 1164-1169.

Galvin, T.J. \& Wyss, J.H. (1996) Screwworm Eradication Program in Central America. Vector-borne pathogens: international trade and tropical animal diseases. Annals of the New York Academy of Sciences, 791, 33-240.

Hammack, L. (1986) Pheromone-mediated copulatory responses of the screwworm fly, Cochliomyia hominivorax. Journal of Chemical Ecology, 12, 1623-1631.

Hammack, L. (1987) Chemical basis for asymmetric mating isolation between strains of screwworm fly, Cochliomyia hominivorax. Journal of Chemical Ecology, 13, 1419-1430.

Hammack, L. (1991) Sex pheromone communication in the screwworm, Cochliomyia hominivorax. Ontogenetic and strain effects. Journal of Chemical Ecology, 17, 2143-2154.

Lindquist, D.A., Abusowa, M. \& Hall, M.J.R. (1992) The New World screwworm fly in Libya: a review of its introduction and eradication. Medical and Veterinary Entomology, 6, 2-8. 
Mackley, J.W. \& Broce, A.B. (1981) Evidence of a female sexrecognition pheromone in the screwworm fly. Environmental Entomology, 10, 406-408.

Mangan, R.L. (1988) Pedigree and heritability influences on mate selectivity and mating aggressiveness in the screwworm, Cochliomyia hominivorax (Diptera: Calliphoridae). Annals of the Entomological Society of America, 81, 649-656.

Montooth, K.L. \& Gibbs, A.G. (2003) Cuticular pheromones and water balance in the housefly, Musca domestica. Comparative Biochemistry and Physiology A, 135, 457-465.
Pomonis, J.G., Hammack, L. \& Hakk, H. (1993) Identification of compounds in an HPLC fraction from female extracts that elicit mating responses in male screwworm flies, Cochliomyia hominivorax. Journal of Chemical Ecology, 19, 985-1008.

Pomonis, J.G. \& Mackley, J. (1985) Gas chromatographic composition profiles of surface lipid extracts from screwworm compared by age, sex, colonization and geography. Southwestern Entomologist, 10, 65-76.

Accepted 10 October 2006

First published online 28 November 2006 